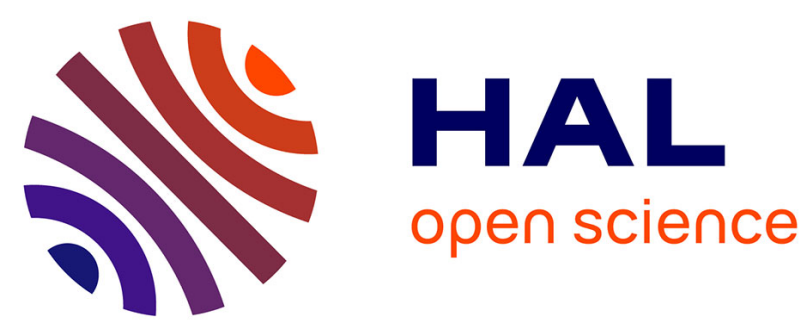

\title{
European clinical guidelines for Tourette Syndrome and other tic disorders. Part III: behavioural and psychosocial interventions
}

\author{
Cara Verdellen, Jolande Griendt, Andreas Hartmann, Tara Murphy
}

\section{- To cite this version:}

Cara Verdellen, Jolande Griendt, Andreas Hartmann, Tara Murphy. European clinical guidelines for Tourette Syndrome and other tic disorders. Part III: behavioural and psychosocial interventions. European Child and Adolescent Psychiatry, 2011, 20 (4), pp.197-207. 10.1007/s00787-011-0167-3 . hal-00683498

\section{HAL Id: hal-00683498 \\ https://hal.science/hal-00683498}

Submitted on 29 Mar 2012

HAL is a multi-disciplinary open access archive for the deposit and dissemination of scientific research documents, whether they are published or not. The documents may come from teaching and research institutions in France or abroad, or from public or private research centers.
L'archive ouverte pluridisciplinaire HAL, est destinée au dépôt et à la diffusion de documents scientifiques de niveau recherche, publiés ou non, émanant des établissements d'enseignement et de recherche français ou étrangers, des laboratoires publics ou privés. 
European clinical guidelines for Tourette Syndrome and other tic disorders. Part III: Behavioural and psychosocial interventions

Cara Verdellen ${ }^{1{ }^{*}}$, Jolande van de Griendt ${ }^{1}$, Andreas Hartmann ${ }^{2}$, Tara Murphy ${ }^{3}$ and the ESSTS Guidelines Group

${ }^{1}$ HSK Group / Expertise Centre Tics, Den Bosch, The Netherlands

${ }^{2}$ Centre de Référence 'Syndrome Gilles de la Tourette', Hòpital de la Pitié-Salpêtrière, Paris, France

${ }^{3}$ Tourette syndrome Clinic, Great Ormond Street Hospital NHS Trust, London, UK

$\S$ Correspondence to:

C. Verdellen, $\mathrm{PhD}$

HSK Group / Expertise Centre Tics

Hambakenwetering 15231 DD

Den Bosch, The Netherlands

Tel.: 031-736429292

Fax: 031-736448801

E-Mail: c.verdellen@hsk.nl

Word count: 3335 (without references), abstract: 177

Tables: 1

Figures: 1 


\section{Abstract}

Objective: This clinical guideline provides recommendations for the behavioural and psychosocial interventions (BPI) of children and adolescents with tic disorders prepared by a working group of the European Society for the Study of Tourette Syndrome (ESSTS).

Method: A systematic literature search was conducted to obtain an update on the efficacy of BPI for tics. Relevant studies were identified using computerized searches of the Medline and PsycINFO databases and the Cochrane Library for the years 1950-2010. The search identified no meta-analyses, yet twelve (systematic) reviews and eight randomized controlled trials provided evidence for the current review.

Results: Most evidence was found for habit reversal training (HRT) and the available but smaller evidence also supports the efficacy of exposure with response prevention (ERP). Both interventions are considered first line behavioural treatments for tics for both children and adults and should be offered to a patient, taking into account his preference. Treatments that are considered second line or add-on behavioural treatments are contingency management, function based interventions and relaxation training. Neurofeedback is still experimental. Almost no research was identified that examined the efficacy of psychosocial interventions, e.g., psychoeducation and group work.

Conclusion: Based on clinical practice, this guideline recommends behavioural treatment as first line offer to patients in most cases. It should be embedded within a psychoeducational and supportive context and can be combined with drug treatment.

\section{Keywords}

Tourette - tic disorders - guidelines - behavioural treatment - psychosocial interventions literature review 


\section{Introduction}

Tic disorders (e.g., chronic motor or vocal tic disorder and Tourette syndrome; TS) are a common developmental disorder among children and adolescents. About $10 \%$ of children have (motor and/or vocal) tics during childhood, which in many cases disappear. However, approximately $1 \%$ of children and adolescents develop TS [1], a condition that is characterized by multiple motor and vocal tics. Often, symptoms of Attention Deficit Hyperactivity Disorder (ADHD), Obsessive Compulsive Disorder (OCD) and Pervasive Developmental Disorder (PDD) coexist. Tics may vary in their severity and in the inconvenience they cause to an individual and his environment. Although not all children and families seek help [2], many require some form of treatment or support to manage their tics and impaired social, emotional and behavioural functioning. The European Society for the Study of Tourette Syndrome (ESSTS) met in November 2008 and in August 2009 to discuss the development of guidelines for the treatment of tic disorders. The present guideline describes recommendations for the behavioural and psychosocial interventions (BPI) of tics in children and adolescents. The behavioural treatment of comorbidity in tic disorders is beyond the scope of this guideline, but some information can be found in Döpfner and Rothenberger [3], Döpfner and Rothenberger [4] and Rothenberger et al. [5].

\section{Method}

To obtain an update on scientific research on the efficacy and effectiveness of BPI for tic disorders, a literature search was performed on behavioural and psychosocial interventions using computerized searches of the Medline (PubMed) and PsycINFO databases (1950 - May 2010). This search was performed using relevant terms (e.g., tics, tic disorder, Tourette's syndrome, behavio(u)r therapy, habit reversal, exposure and response prevention, relaxation, psychoeducation, support group, coping strategies). 'Map term to subject heading', in which 
the best-matching subject headings associated with a term are included, was used. In addition, the reference lists of the (review) articles identified through Medline and PsychINFO were reviewed for additional studies. The search produced an initial list of 159 publications, which revealed no meta-analyses, twelve (systematic) reviews, eight randomized controlled trials (RCT's) and one non-randomized controlled trial. Furthermore, multiple case studies were found. No studies were found on tic disorders comparing behaviour therapy with pharmacotherapy. The Cochrane library was also consulted and contained no information on BPI for tic disorders. Although the publication list comprises many relevant articles related to the subject, it should be noted that it is not exhaustive.

\section{Results}

\section{Behavioural interventions}

The most rigorously researched of all psychological interventions are behavioural treatments. Overall, eight different behavioural treatments for tics were identified in the literature: massed (negative) practice (MP), habit reversal (HR), self-monitoring (SM), contingency management $(\mathrm{CM})$ /function based interventions $(\mathrm{FBI})$, relaxation training $(\mathrm{RT}) /$ hypnosis, exposure and response prevention (ER), cognitive-behavioural treatment (CBT) and bio(neuro)feedback (NF). Most studies utilized single-case experimental designs, using a multiple baseline design, a waiting list design (WL) or an alternating treatments design. Nine studies employed group-based methodology, eight of these with random assignment to treatment conditions. RCT's differed from one another on several variables (e.g., tic disorder, HR ingredients, sample age, outcome measures, duration of follow-up). Four studies included both children and adults, but only two studies consisted of children (age 7-18) only. Table 1 provides an overview of the RCT's of tic disorders. 


\section{Massed (negative) practice (MP)}

MP is the oldest behavioural treatment for tics reported in the literature. MP involves the repeated, rapid, voluntary and effortful performance of tics for a specified period of time (e.g., 30 minutes), interspersed with brief periods of rest. The majority of single case studies into MP failed to find a decrease in tic frequency. In the one RCT comparing MP to HR in both children and adults with TS, MP failed to produce reductions in tics comparable to those produced by the HR condition [6] (see Table 1). Overall, it can be concluded that MP has limited therapeutic value for tic disorders.

\section{Habit Reversal (HR)}

HR is the most extensively researched behavioural treatment for tics. It offers a set of techniques that help the patient become aware of the occurrence of a tic, followed by a socalled competing response training to interrupt or inhibit the tic [7-9]. HR may also comprise relaxation training, contingency management, and generalization training. Awareness of the tics is enhanced through response description, response detection, an early warning procedure, and situation awareness training. With competing response training the patient learns to initiate a response for 1 to 3 minutes, or until the urge goes away, contingent upon the urge to perform a tic or after the actual occurrence of the tic. Several dozens of uncontrolled studies into HR report tic reductions of 30 to $100 \%$. Most studies involved small patient samples with unspecified diagnostic criteria. However, eight RCT's (see Table 1) were performed into HR indicating its' efficacy. Four studies were performed on adults only (age 18-60) [10-13], 1 study (the largest study up to date, $\mathrm{N}=126$ ) included children only (age 9-17) [14] and 3 studies included both children and adults (age 6-62) [6,8,15]. Most studies consisted of 10 to 
14 weekly sessions $[10-13,15]$. Some studies spreaded the sessions over time after starting with weekly sessions, e.g. biweekly or monthly sessions. Follow-up data of at least 10 months duration showed maintenance of results. More information can be found in table 1 . In addition to the RCT's, several review articles support evidence for HR [16-21]. Awareness training and competing response training seem to be the active components of the multi-component HR package that are necessary and sufficient for tic reduction [22]. In summary, studies indicate that HR is effective for both vocal and motor tics, for children as well as adults, for patients receiving TS medications as well as those not doing so, for tic severity as well as tic frequency, and with no evidence of symptom substitution [23].

\section{Self-monitoring (SM)}

SM consists of having the patient record tics during a specified period by using a counter or a notebook. The goal is to identify when and in which situation a tic occurs. SM is often applied in multi-component treatment (HR) packages. Only a few case studies have been conducted in which SM was used as the primary treatment procedure, indicating that SM generally results in temporary improvement [24]. Immediate, rather than delayed recording of tics appears to be essential for tic reduction $[25,26]$. In summary, there is some support for the usefulness of SM, although the generalizability and durability of treatment gains remain unclear.

\section{Contingency management (CM)/Function based interventions (FBI)}

$\mathrm{CM}$ consists of the manipulation of environmental contingencies, so that tic-free intervals are positively reinforced and tic behaviours are ignored. Using tokens to reinforce the absence of tics is an example of a CM-based intervention [27]. CM is mostly used in multi-component treatment packages, making it difficult to assess the unique value of this specific technique. A more specialized type of CM is known as 'function based interventions' (FBI). In FBI, factors 
specific to the individual's unique environment are indentified which increase or decrease tics. The factors are altered to provide tic reductions. The effect of this intervention is reported in single case studies [28].

\section{Relaxation training $(R T)$}

The use of RT in the treatment of tics is based on the observation that increases in stress and anxiety result in concomitant increases in tic performance. Hence, tic reduction in RT might work indirectly via stress reduction. Relaxation can help reduce muscular tension. RT includes deep breathing, progressive muscle training, and imagery, and is mostly applied as part of a multi-component treatment. Two studies examined RT as a mono-component treatment under controlled conditions. Peterson and Azrin [24] found that RT resulted in an average tic decreases of $32 \%(\mathrm{~N}=6)$, which was less than the effect of competing response training (55\% decrease) or SM (45\% decrease). Bergin et al. [29] conducted a controlled, randomized trial in children (age 7-18) comparing RT with minimal control therapy. After six weekly sessions, they found no differences between groups in terms of tic symptom severity (see Table 1). Improvements in tic symptoms were only short-term. In summary, it can be concluded that RT is not an evidence based treatment for tics, although it may have some merit in the short term. Hypnosis and cue-controlled relaxation, more specific forms of relaxation, have been shown useful in some cases $[30,31]$ and need further study.

\section{Exposure and response prevention (ER)}

The application of ER to reduce tics is based on the association of unpleasant premonitory sensations followed by a motor or vocal tic that relieves the sensation [32]. In learning theory terms, tics can be viewed as conditioned responses to premonitory, interoceptive stimuli. When such stimuli reoccur over time, the power of the associative interaction between the 
sensations and the resultant tic behaviour is strengthened. ER aims at interrupting the association, thus preventing the tics to occur. By confronting patients for a prolonged period of time with the sensations (exposure) and resisting the tic (response prevention), the patients might learn to tolerate the unpleasant sensation (habituation). Habituation will lessen the urge or need to give in to the tic, resulting in a reduction of tic behaviour. One RCT comparing 12 2-hour ER sessions (including 2 training sessions) with 10 1-hour HR sessions [15] revealed no differences between conditions (see Table 1). The study included both children and adults (age 7-55) with TS. Effect sizes were larger for ER than for HR. Results of this RCT and of a few case studies into ER [33] provide support for ER and indicate the need for further study. Also, review articles [17-20] suggest that ER is a promising treatment for tics. Preliminary results indicate that ER is effective for vocal and motor tics, for children as well as adults, for tic severity as well as tic frequency, with no indications of a rebound effect [34]. Since younger children are less aware of premonitory sensory motor phenomena it has to be clarified if there is an age effect respective an age limit for ER but also for HR [35].

\section{Cognitive behavioural treatment (CBT)}

Two studies (both included adults only) were identified that employed cognitive behavioural interventions (see table 1). The cognitive component of the intervention consisted of mentally challenging and restructuring the way patients evaluated their expectations and actions in high-risk situations related to frequent ticcing behaviour. One study compared CBT with HR in CTD and found comparable results for both treatments [12]. In another study CBT combined with HR in CTD was found superior to WL [13]. The value of cognitive interventions in the treatment of tics remains to be investigated separately, as studies into CBT included a HR component, thus making its unique contribution to the results unclear. 
Preliminary results seem to indicate that cognitive interventions have no specific additive value in the treatment of tics.

\section{Bio(neuro)feedback (NF)}

NF is aimed at self-directed modulating of defined parts of brain electrical activity [36]. It is based on operant conditioning; when brain activity changes in the desired direction, a positive 'reward' feedback is given to the individual.

Two case studies on TS (both $\mathrm{N}=2$ ) were found, one with positive results [37], the other with inconclusive results [38]. Also, a study in 15 TS patients showed significantly lower tics during relaxation biofeedback compared to arousal biofeedback [39]. Considering the lack of randomized controlled research on NF and biofeedback for the treatment of tics, further research is required to allow for conclusions to be drawn.

\section{Psychosocial interventions}

The literature search and recent reviews by Cook and Blacher [17] and Woods, Piacentini, \& Walkup [40] indicate there is no evidence-based practice with regard to supportive psychosocial interventions in TS. There is limited literature guiding interventions which modify the child's environment (parents, teachers, peers) to facilitate reduction of tics and enhance quality of life $[41,42]$. However, education about tic disorders and the provision of support and reassurance to patients and their families have been described as the cornerstone for all other treatment interventions [43]. Therefore, based on clinical practice rather than empirical evidence, the present guideline includes recommendations on these approaches.

\section{Psychoeducation}


It is broadly accepted that TS and related tic disorders affect the lives of patients and all family members. Specifically, family members often have difficulty adjusting to the diagnosis and may struggle to manage with comorbid difficulties such as anger outbursts and hyperactivity [44]. Psychoeducation represents an important component in providing support and resolving misunderstanding, uncertainty and stigma in TS [45]. Information about the natural course of TS and helping the child and his environment to identify personal strengths often serves to reduce anxiety. It is proposed to provide relevant information to a child about the condition. This will promote coping strategies and self-efficacy and provide the child with the tools to explain to others (especially teachers and schoolmates) about the disorder. Providing educators with general information relating to the aetiology, presentation, and course of TS will help them to implement effective individualised strategies to manage classroom behaviour, thereby allowing the child to maximize learning potential. Due to the rapidly changing nature of TS, Kepley \& Conners [46] highlight the need for a flexible approach, close liaison between parents and teachers and frequent re-evaluation of interventions within education to ensure effective management.

Children with TS report that they struggle to fit into society's expectations and rate associated embarrassment as disabling as the tics themselves [45,47]. Young people with TS have been rated as less socially favourably as other non-affected peers in studies using laboratory-based paradigms [48-50]. Two studies have looked at peer-perceptions of TS and the effects of psychoeducation through a video-tape intervention [49,51]. In one study, older students viewed a TS-specific educational video. These students reported more positive attitudes toward people with tics than those who viewed other non-TS related material [51]. Another study involving younger children showed no difference in attitudes following presentation of psychoeducational material. The effect on social behaviour intentions and actual social behaviour remains unclear and further research in this area is needed. 


\section{Group work}

Case studies have been published describing and evaluating group work targeting different symptoms in children with TS. Group approaches offer children and their parents the opportunity to meet one another within a supportive environment. Groups can provide psychoeducational material [52] on aspects of TS such as tic management, anger management, bullying and school and self-esteem. Although the approach remains at the descriptive stage, qualitative feedback following such interventions has been positive and it seems worthy of further evaluation.

\section{Charities and support organisations}

The preponderance of charities for people with TS throughout the world are a vehicle for sharing information on TS. Taubert [53] discusses the important role of voluntary organizations in supporting people with TS and their families. Large organisations such as the Tourette Syndrome Association in the US provide care and advocacy. Meanwhile, several European self-help organizations (e.g. in Germany, France, the Netherlands) are also quite active. While support groups for families are important, a more holistic approach between professionals, charities and government bodies may also be key role for such organisations.

\section{Conclusions}

The literature review provides scientific evidence for the behavioural treatment of tics in tic disorders. Most studies investigated the effectiveness of HR. Based on eight RCT's, several review articles and dozens of case studies, HR can be considered an evidence based behavioural treatment for tics for both children and adults. HR was found superior to WL [8,13], MP [6], and SP [10,11,14], and equally effective as ER [15]. A number of RCT's have 
shown that the improvement of HR continues up to at least ten months following completion of treatment. The literature also provides support for ER. In one RCT [15] comparing ER with HR, larger effect sizes were found for ER than for HR, indicating its efficacy. In addition, several review articles and a few case studies demonstrate that ER is a promising, probably efficacious treatment for tic disorders for both children and adults, which needs further research.

Although most evidence was found for HR and, to a lesser extent, for ER, the current literature base is limited by the availability of only one (albeit large-scale) RCT [14] with a child and adolescent-only sample. Therefore, firm conclusions for these specific age groups cannot be drawn. Comparability of the RCT's was limited by the different outcome measures that were used, application of different HR ingredients, different sample ages, number of sessions, and follow-up periods. Only three RCT's [10,14,15] reported effect sizes. In order to enable comparisons of efficacy, future studies are encouraged to include such calculations. There are no controlled studies into the efficacy and effectiveness of other psychosocial interventions, e.g., psychoeducation or support groups. Therefore, these interventions are not to be considered fully evidence based, although the importance of these interventions is emphasized in clinical practice.

\section{Recommendations}

Based on the evidence at present and clinical support this guideline recommends both HR and ER as first line behavioural treatments for tics for both children and adults. HR has a broader evidence base and is usually offered. Results indicate that ER may be more effective than HR at the severe end of TS, i.e., when many tics are involved [15]. However, ER as applicated in the RCT took twice as much therapy time as HR, i.e., studies were based on sessions lasting 2 hours each, whereas HR sessions usually last 1 hour. Recent research shows that ER sessions 
lasting for 1 hour had comparable results [54]. Other treatments for tics were identified in the literature, for which insufficient evidence was found. MP, the oldest behavioural treatment for tics reported in the literature, lacks evidence and therefore is not recommended as a treatment for tics. CM/reinforcement techniques and FBI are also not to be considered evidence based treatments for tics. However, case studies indicate that these interventions have some value in specific cases and need further research. CM may be a useful tool for children, because motivation for a behavioural treatment may not be intrinsic and its reward (i.e., tic reductions) may be too far away for a child. Based on the current literature, $\mathrm{CM}$ and FBI are recommended as second line behavioural interventions. RT, although also not to be considered an evidence based treatment for tics, is recommended as a second line behavioural treatment for tics as well. Case studies indicate that patients can benefit from this treatment to some extent and hypnosis and cue-controlled relaxation were found to reduce tics merely via stress reduction in specific cases. Cognitive interventions, although these have not been studied in adolescents, do not seem to have additive value to HR. Therefore, at present, this method is not recommended as an intervention for tics. Based on the sparse and inconclusive literature on the efficacy of NF, this method cannot yet be recommended as a treatment for tics. However, a RCT in children with ADHD showed a long-term improvement on selfregulation of behaviour, which seems promising also for TS, especially in cases where TS and ADHD may coexist $[55,56]$. NF should thus be further evaluated as a treatment for tics. Although there are no controlled studies into the efficacy and effectiveness of other psychosocial interventions, e.g., psychoeducation, bibliotherapy, self help, social support groups, this guideline recommends embedding each treatment within a psychoeducational and supportive context. Psychoeducation alone may also be useful for families who do not engage with more comprehensive treatments due to very mild tics or lack of services. Specific interventions must target not only tic symptoms, but also comorbid problems and coping 
strategies that can profoundly influence the impact that TS may have on an individual's well being during childhood and later into adulthood. The present guideline does not provide recommendations as to the behavioural treatment of comorbidity in tic disorders.

Include Figure 1 here

A summary of the recommendations of this guideline is presented in a flowchart (see Figure 1). Psychoeducation is recommended in all (both mild and more severe) cases. Other supportive interventions (e.g., liaison with school, group work, social skills training) are recommended in individual cases depending on the specific needs of a child and his environment. HR and ER are behavioural treatments recommended as first line treatments to patients who want to reduce their tics. In helping a child or adolescent (and his family) making a choice which treatment to start with, information should be given about both treatments. This guideline recommends to evaluate treatment response after 10 sessions, and to continue treatment for another 10 sessions when there is a partial response, to start the alternative treatment when there is no response, and to consider medication when both treatments have not resulted in relevant tic reductions. In case of severe symptoms, it is recommended to consider combining a behavioural treatment with medication or starting medication first and adding behavioural treatment later. Based on research at present, weekly sessions of 1 hour are advised in HR and weekly sessions of 2 hours in ER. In addition, second line interventions such as CM, FBI or RT are recommended in individual cases, when first line interventions do not suffice. 


\section{Figure 1}

Decision tree of psychological interventions for tics in tic disorders

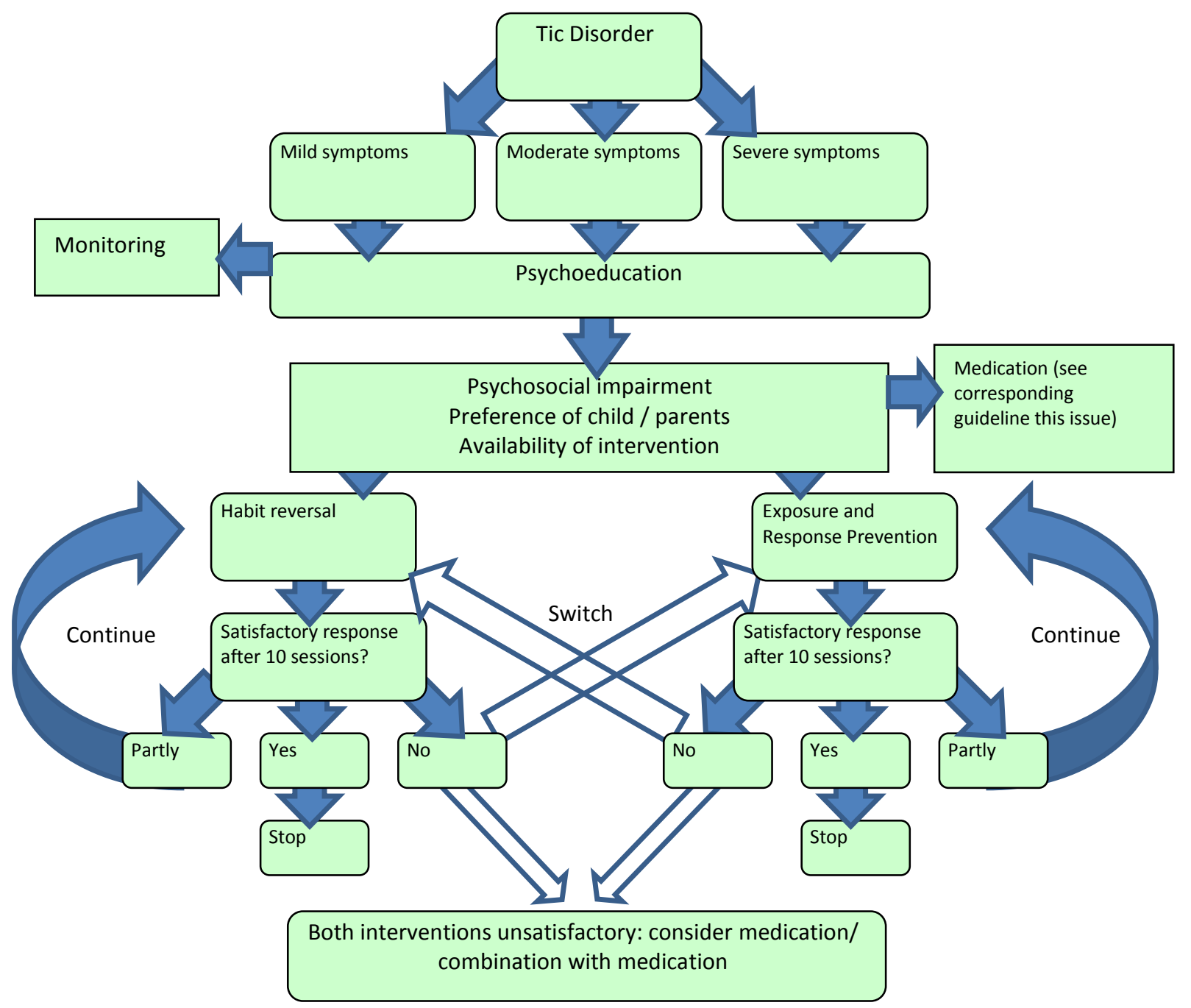




\section{Table 1}

Randomized controlled trials of behavioural interventions for tics disorders (divided according to the inclusion or exclusion of children)

\begin{tabular}{|c|c|c|c|c|c|c|}
\hline Study & $\begin{array}{l}\text { Interven- } \\
\text { tions }\end{array}$ & Subjects & Outcome & Efficacy & Follow-up & Comments \\
\hline $\begin{array}{l}\text { Azrin et al., } \\
1980\end{array}$ & $\begin{array}{l}\mathrm{HR}, \mathrm{MP} \\
\text { parallel }\end{array}$ & $\begin{array}{l}22 \text { TS } \\
\text { patients } \\
\text { (age 11-62, } \\
\text { average } \\
30,5 \text { ) }\end{array}$ & $\mathrm{HR}>\mathrm{MP}^{* *}$ & $\begin{array}{l}\text { Tic frequency (self-report of number of tic } \\
\text { episodes): } \\
\text { HR: } 84 \% \text { decrease } \\
\text { MP: }+/-30 \% \text { decrease }\end{array}$ & $\begin{array}{l}1 \text { month: } \\
\text { HR: } 92 \% \text { decrease } \\
\text { MP: }+--30 \% \text { decrease } \\
\text { 4-6 months: } \\
\text { HR: } 99 \% \text { decrease } \\
18 \text { months: } \\
\text { HR: } 97 \% \text { decrease }\end{array}$ & $\begin{array}{l}\text { - } 1 \text { or } 2 \text { sessions (2,5 hours) } \\
\text { - } \mathrm{HR} \text { consisted of competing response training and gene } \\
\text { behaviour therapy procedures } \\
\text { - FU: telephone calls } \\
\text { - No further FU data on MP }\end{array}$ \\
\hline $\begin{array}{l}\text { Azrin \& } \\
\text { Peterson, } 1990\end{array}$ & $\begin{array}{l}\text { HR, WL } \\
\text { Crossover }\end{array}$ & $\begin{array}{l}10 \text { TS } \\
\text { patients } \\
\text { (age 6-36, } \\
\text { average } \\
18,1 \text { ) } \\
\end{array}$ & $H R>W L^{*}$ & $\begin{array}{l}\text { Tic frequency (self-report \& independent video } \\
\text { rating): } \\
\text { HR: } 93 \% \text { decrease at home (self-report); } 93,5 \% \text { at } \\
\text { clinic (independent video rating) } \\
\text { WL: no significant decrease }\end{array}$ & No follow-up & $\begin{array}{l}\text { - Mean of } 20 \text { sessions (range } 13-30 \text { ) during } 8-11 \text { months } \\
\text { - HR consisted of awareness training, self-monitoring, c c } \\
\text { response training, relaxation training and contingency ma }\end{array}$ \\
\hline $\begin{array}{l}\text { Verdellen et } \\
\text { al., } 2004\end{array}$ & $\begin{array}{l}\text { HR, ER } \\
\text { parallel }\end{array}$ & $\begin{array}{l}3 \text { TS } \\
\text { patients } \\
\text { (age } 7-55, \\
\text { average } \\
20,6)\end{array}$ & $\mathrm{HR}=\mathrm{ER}$ & $\begin{array}{l}\text { YGTSS: } \\
\text { ER: } 26.2 \text { pre } 17.6 \text { post (ES } 1.42 \text { ) } \\
58 \% \text { of patients showed }>30 \% \text { reduction } \\
\text { HR: } 24.1 \text { pre } 19.7 \text { post (ES } 1.06 \text { ) } \\
28 \% \text { of patients showed }>30 \% \text { reduction } \\
\text { Tic frequency clinic (independent video rating): } \\
\text { ER: } 74 \% \text { of patients showed }>30 \% \text { reduction (ES } 0.90 \text { ) } \\
\text { HR: } 53 \% \text { of patients showed }>30 \% \text { reduction (ES } 0.47 \text { ) } \\
\text { Tic frequency home (report of parent/partner): } \\
\text { ER: } 89 \% \text { of patients showed }>30 \% \text { reduction (ES } 0.88 \text { ) } \\
\text { HR: } 72 \% \text { of patients showed }>30 \% \text { reduction (ES } 0.73 \text { ) }\end{array}$ & $\begin{array}{l}\text { 3 months: } \\
\text { YGTSS: } \\
\text { ER: } 14.0 \text { (ES 1.49) } \\
\text { HR: } 13.5 \text { (ES 1.95) }\end{array}$ & $\begin{array}{l}\text { - } 12 \text { sessions ER ( } 2 \text { hours, weekly) vs } 10 \text { sessions HR ( } \\
\text { weekly) } \\
\text { - Weighted gain scores were used to correct for number } \\
\text { - HR consisted of awareness training and competing res } \\
\text { training } \\
\text { - HR and ER improved significantly on all measurement } \\
\text { - FU included } 25 \text { patients who had received the alternati } \\
\text { condition }\end{array}$ \\
\hline $\begin{array}{l}\text { Bergin et al., } \\
1997\end{array}$ & $\begin{array}{l}\mathrm{RT}, \mathrm{MT} \\
\text { parallel }\end{array}$ & $\begin{array}{l}23 \mathrm{TS} \\
\text { patients } \\
\text { (age } 7-18, \\
\text { average } \\
11,3)\end{array}$ & $\mathrm{RT}=\mathrm{MT}$ & $\begin{array}{l}\text { YGTSS: } \\
\text { RT: } 86 \% \text { of patients improved (non-significant) } \\
\text { MT: } 66 \% \text { of patients improved (non-significant) }\end{array}$ & $\begin{array}{l}6 \text { weeks: } \\
\text { YGTSS: } \\
\text { RT: } 71 \% \text { of patients improved } \\
\text { (non-significant) } \\
\text { MT: } 55 \% \text { of patients improved } \\
\text { (non-significant) }\end{array}$ & $\begin{array}{l}\text { - } 6 \text { sessions (1 hour, weekly) } \\
\text { - No significant improvements } \\
\text { - Comparable results on other tic severity measurements } \\
\text { Videotape Scale, Hopkins Motor and Vocal Tic Scale, } \\
\text { Syndrome Severity Scale) }\end{array}$ \\
\hline $\begin{array}{l}\text { Piacentini et } \\
\text { al., } 2010\end{array}$ & $\begin{array}{l}\mathrm{HR}, \mathrm{SP} \\
\text { parallel }\end{array}$ & $\begin{array}{l}126 \mathrm{TS} / \mathrm{CTD} \\
\text { patients } \\
\text { (age } 9-17\end{array}$ & $\mathrm{HR}>\mathrm{SP}$ & $\begin{array}{l}\text { YGTSS: } \\
\text { HR: } 24.7 \text { pre- } 17,1 \text { post (ES } 0.68) \\
\text { SP: } 24.6 \text { pre- } 21,1 \text { post }\end{array}$ & $\begin{array}{l}3 \text { months: } \\
\text { YGTSS: } \\
\text { HR:13.9 }(n=23)\end{array}$ & $\begin{array}{l}\text { - } 8 \text { sessions (during } 10 \text { weeks; first two sessions } 1,5 \text { hol } \\
\text { remaining sessions } 1 \text { hour) } \\
\text { - } 3 \text { monthly booster sessions for responders }\end{array}$ \\
\hline
\end{tabular}




\begin{tabular}{|c|c|c|c|c|c|c|}
\hline & & $\begin{array}{l}\text { average } \\
11,7)\end{array}$ & & & $\begin{array}{l}\text { SP: } 9.9(n=6) \\
6 \text { months: } \\
\text { YGTSS: } \\
\text { HR: } 13.3(n=23) \\
\text { SP: } 10.4(n=6)\end{array}$ & $\begin{array}{l}\text { - HR consisted of awareness training, competing respon } \\
\text { training, relaxation training and function based interven } \\
\text { - SP consisted of supportive psychotherapy and educati } \\
\text { - Significantly more children receiving HR were rated as } \\
\text { very much improved or much improved on the Clinical } \\
\text { Impression-improvement scale (52.5\% vs } 18.5 \%) \\
\text { - } 3 \text { and } 6 \text { months follow-up: results remained stable for t } \\
\text { available responders }\end{array}$ \\
\hline $\begin{array}{l}\text { Wilhelm et al., } \\
2003\end{array}$ & $\begin{array}{l}\mathrm{HR}, \mathrm{SP} \\
\text { parallel }\end{array}$ & $\begin{array}{l}32 \text { TS } \\
\text { patients } \\
\text { (average } \\
\text { age } 36,2)\end{array}$ & $\mathrm{HR}>\mathrm{SP}^{*}$ & $\begin{array}{l}\text { YGTSS: } \\
\text { HR: } 30.5 \text { pre- } 19.8 \text { post (ES 1.50) } \\
\text { SP: } 26.6 \text { pre- } 26.9 \text { post (ES }-0.03 \text { ) }\end{array}$ & $\begin{array}{l}10 \text { months: } \\
\text { YGTSS: } \\
\text { HR: } 21.0 \text { (still significantly } \\
\text { improved) } \\
\text { SP: } 23.8 \text { (pre-treatment level) }\end{array}$ & $\begin{array}{l}\text { - } 14 \text { sessions (8 weekly, } 6 \text { 2-weekly) } \\
\text { - HR consisted of self-monitoring, competing response t } \\
\text { relaxation training and contingency management } \\
\text { - HR improved significantly on the Clinical Global Impres } \\
\text { improvement scale (CGI-i) as well, SP not } \\
\text { - } 10 \text { months FU: no significant difference between HR ar } \\
\text { the YGTSS; significant difference between HR and SP } \\
\text { maintained on the CGI-i }\end{array}$ \\
\hline $\begin{array}{l}\text { Deckersbach et } \\
\text { al., } 2006\end{array}$ & $\begin{array}{l}\mathrm{HR}, \mathrm{SP} \\
\text { paralell }\end{array}$ & $\begin{array}{l}30 \text { TS } \\
\text { patients } \\
\text { (average } \\
\text { age } 35,1)\end{array}$ & $\mathrm{HR}>\mathrm{SP}^{*}$ & $\begin{array}{l}\text { YGTSS: } \\
\text { HR: } 39.3 \text { pre- } 18.3 \text { post } \\
\text { SP: } 27.7 \text { pre- } 26.8 \text { post }\end{array}$ & $\begin{array}{l}6 \text { months: } \\
\text { YGTSS: } \\
\text { HR: } 18.4 \\
\text { SP: } 26.6\end{array}$ & $\begin{array}{l}\text { - } 14 \text { sessions (8 weekly, } 4 \text { 2-weekly, } 2 \text { monthly) } \\
\text { - HR consisted of awareness training, self-monitoring, c c } \\
\text { response training, relaxation training and contingency } \\
\text { management } \\
\text { - Both groups improved in life-satisfaction and psychoso } \\
\text { functioning; only HR improved significantly in tic severi } \\
\text { - } 6 \text { months FU: results remained stable }\end{array}$ \\
\hline $\begin{array}{l}\text { O'Connor et } \\
\text { al., } 2001\end{array}$ & $\begin{array}{l}\text { HR/CBT, WL } \\
\text { Crossover }\end{array}$ & $\begin{array}{l}47 \text { CTD } \\
\text { patients }\end{array}$ & $\mathrm{HR} / \mathrm{CBT}>\mathrm{WL}^{*}$ & $\begin{array}{l}\text { Tic frequency and intensity (diary, video): } \\
\text { HR/CBT: } 88 \% \text { of patients significant decrease in }\end{array}$ & $\begin{array}{l}2 \text { months: } \\
\text { Tic frequency, intensity and }\end{array}$ & $\begin{array}{l}\text { - Group non-RCT design } \\
\text { - } 12 \text { sessions (weekly) }\end{array}$ \\
\hline
\end{tabular}




\begin{tabular}{|c|c|c|c|c|c|}
\hline & & \begin{tabular}{|l|} 
(age 18-60, \\
average \\
$39,1)$
\end{tabular} & $\begin{array}{l}\text { frequency and intensity on diary and video measures } \\
\text { WL: no significant decrease } \\
\text { Degree of control: } \\
\text { HR/CBT: } 65 \% \text { of patients reported between } 75 \text { and } \\
100 \% \text { control }\end{array}$ & $\begin{array}{l}\text { degree of control: } \\
\text { HR/CBT: maintained results } \\
2 \text { years: } \\
\text { Degree of control: } \\
\text { HR/CBT: } 52 \% \text { of patients } \\
\text { maintained } 75-100 \% \text { control }\end{array}$ & $\begin{array}{l}\text { - Both tic disorders ( } n=47 \text { ) and habit disorders ( } n=43 \text { ) we } \\
\text { included } \\
\text { - HR consisted of awareness training, competing respon } \\
\text { training, relaxation training, relapse prevention and wa } \\
\text { accompanied with more general cognitive and behavio } \\
\text { restructuring } \\
\text { - } 2 \text { years FU: interview by telephone }\end{array}$ \\
\hline
\end{tabular}

Children \& Adults

Children only

Adults only

$\mathrm{TS}=$ Tourette Syndrome; $\mathrm{CTD}=$ chronic tic disorder; $\mathrm{MP}=$ massed practice; $\mathrm{WL}=$ waiting list; $\mathrm{HR}=$ habit reversal; $\mathrm{ER}=$ exposure and response prevention; RT=relaxation training; $\mathrm{MT}=$ minimal therapy; $\mathrm{SP}=$ supportive psychotherapy; $\mathrm{CBT}=$ cognitive behavioural therapy; $\mathrm{YGTSS}=\mathrm{Yale}$ Global Tic Severity Scale; * = significant difference $\mathrm{p}<0.05 ; * *=$ significant difference $\mathrm{p}<0.01$; ES=effect size; FU=follow-up 


\section{References}

1. Robertson MM (2008) The prevalence and epidemiology of Gilles de la Tourette syndrome. Part 1: the epidemiological and prevalence studies. J Psychosom Res 65 (5):461472. doi:S0022-3999(08)00111-6 [pii]

10.1016/j.jpsychores.2008.03.006

2. Schlander M, Schwarz O, Rothenberger A, Roessner V (2010) Tic disorders: Administrative prevalence and co-occurrence with attention-deficit/hyperactivity disorder in a German community sample. Eur Psychiatry. doi:S0924-9338(09)00181-3 [pii] 10.1016/j.eurpsy.2009.10.003

3. Döpfner M, Rothenberger A (2007) Behavior therapy in tic-disorders with co-existing ADHD. Eur Child Adolesc Psychiatry 16 Suppl 1:89-99. doi:10.1007/s00787-007-1011-7

4. Döpfner M, Rothenberger A (2007) Tic- und Zwangsstörungen; Themenschwerpunkt. Kindheit und Entwicklung 16:75-138

5. Rothenberger A, Roessner V, Banaschewski $\mathrm{T}$ (2006) Habit formation in Tourette Syndrome with associated obsessive-compulsive behaviour: At the crossroads of neurobiological modelling. Behavioral and Brain Sciences 29:627-628

6. Azrin NH, Nunn RG, Frantz SE (1980) Habit reversal vs negative practice treatment of nervous tics. Behavior Therapy 11 (2):169-178

7. Azrin NH, Nunn RG (1973) Habit reversal: A method of eliminating nervous habits and tics. Behaviour Research and Therapy 11:619-628

8. Azrin NH, Peterson AL (1990) Treatment of Tourette Syndrome by habit reversal: A waiting-list control group comparison. Behavior Therapy 21 (3):305-318

9. Woods DW, Miltenberger RG (1995) Habit reversal: a review of applications and variations. J Behav Ther Exp Psychiatry 26 (2):123-131. doi:0005791695000090 [pii] 
10. Wilhelm S, Deckersbach T, Coffey BJ, Bohne A, Peterson AL, Baer L (2003) Habit reversal versus supportive psychotherapy for Tourette's disorder: a randomized controlled trial. Am J Psychiatry 160 (6):1175-1177

11. Deckersbach T, Rauch S, Buhlmann U, Wilhelm S (2006) Habit reversal versus supportive psychotherapy in Tourette's disorder: a randomized controlled trial and predictors of treatment response. Behav Res Ther 44 (8):1079-1090. doi:S0005-7967(05)00178-6 [pii] 10.1016/j.brat.2005.08.007

12. O'Connor K, Gareau D, Borgeat F (1997) A comparison of a behavioural and a cognitivebehavioural approach to the management of chronic tic disorders. Clinical Psychology and Psychotherapy 4:105-117

13. O'Connor KP, Brault M, Robillard S, Loiselle J, Borgeat F, Stip E (2001) Evaluation of a cognitive-behavioural program for the management of chronic tic and habit disorders. Behav Res Ther 39 (6):667-681. doi:S0005-7967(00)00048-6 [pii]

14. Piacentini J, Woods DW, Scahill L, Wilhelm S, Peterson AL, Chang S, Ginsburg GS, Deckersbach T, Dziura J, Levi-Pearl S, Walkup JT (2010) Behavior therapy for children with Tourette disorder: a randomized controlled trial. JAMA 303 (19):1929-1937. doi:303/19/1929 [pii]

10.1001/jama.2010.607

15. Verdellen CW, Keijsers GP, Cath DC, Hoogduin CA (2004) Exposure with response prevention versus habit reversal in Tourettes's syndrome: a controlled study. Behav Res Ther 42 (5):501-511. doi:10.1016/S0005-7967(03)00154-2

S0005796703001542 [pii]

16. Carr JE, Chong IM (2005) Habit reversal treatment of tic disorders: a methodological critique of the literature. Behav Modif 29 (6):858-875. doi:29/6/858 [pii]

$10.1177 / 0145445505279238$ 
17. Cook CR, Blacher J (2007) Evidence-based psychosocial treatments for tic disorders. Clinical Psychology: Science and Practice 14 (3):252-267

18. Himle MB, Woods DW, Piacentini JC, Walkup JT (2006) Brief review of habit reversal training for Tourette syndrome. J Child Neurol 21 (8):719-725

19. Peterson AL (2007) Psychosocial management of tics and intentional repetitive behaviors associated with Tourette syndrome. In: Woods DW, Piacentini JC, Walkup JT (eds) Treating Tourette syndrome and tic disorders: A guide for practitioners. Guilford Press, New York, pp $154-184$

20. Piacentini J, Chang S (2001) Behavioral treatments for Tourette syndrome and tic disorders: state of the art. Adv Neurol 85:319-331

21. Piacentini J, Chang S (2005) Habit reversal training for tic disorders in children and adolescents. Behav Modif 29 (6):803-822. doi:29/6/803 [pii]

$10.1177 / 0145445505279385$

22. Miltenberger RG, Fuqua RW, McKinley T (1985) Habit reversal with muscle tics: Replication and component analysis. Behavior Therapy 16 (1):39-50

23. Woods DW, Conelea CA, Walther MR (2007) Barriers to dissemination: Exploring the criticisms of behavior therapy for tics. Clinical Psychology: Science and Practice 14:279-282

24. Peterson AL, Azrin NH (1992) An evaluation of behavioral treatments for Tourette syndrome. Behav Res Ther 30 (2):167-174. doi:0005-7967(92)90140-C [pii]

25. Billings A (1978) Self-monitoring in the treatment of tics: A single-subject analysis. Journal of Behavior Therapy and Experimental Psychiatry 9 (4):339-342

26. Turpin G, Powell GE (1984) Effects of massed practice and cue-controlled relaxation on tic frequency in Gilles de la Tourette's syndrome. Behav Res Ther 22 (2):165-178. doi:00057967(84)90105-0 [pii] 
27. Woods DW, Himle MB (2004) Creating tic suppression: comparing the effects of verbal instruction to differential reinforcement. J Appl Behav Anal 37 (3):417-420. doi:10.1901/jaba.2004.37-417

28. Watson TS, Sterling HE (1998) Brief functional analysis and treatment of a vocal tic. J Appl Behav Anal 31 (3):471-474. doi:10.1901/jaba.1998.31-471

29. Bergin A, Waranch HR, Brown J, Carson K, Singer HS (1998) Relaxation therapy in Tourette syndrome: a pilot study. Pediatr Neurol 18 (2):136-142. doi:S0887899497002002 [pii]

30. Culbertson FM (1989) A four-step hypnotherapy model for Gilles de la Tourette's syndrome. American Journal of Clinical Hypnosis 31:252-256

31. Hoogduin K, Cazemier B, Verdellen C (1995) Exposure, responspreventie en zelfcontrole bij Gilles de la Tourette-patiënten [Exposure, response prevention and self-control in patients with Gilles de la Tourette syndrome]. Gedragstherapie 28:31-40

32. Leckman JF, Walker DE, Cohen DJ (1993) Premonitory urges in Tourette's syndrome. Am J Psychiatry 150 (1):98-102

33. Hoogduin C, Verdellen C, Cath D (1997) Exposure and response prevention in the treatment of Gilles de la Tourette's syndrome: Four case studies. Clinical Psychology and Psychotherapy 4:125-137

34. Verdellen CW, Hoogduin CA, Keijsers GP (2007) Tic suppression in the treatment of Tourette's syndrome with exposure therapy: the rebound phenomenon reconsidered. Mov Disord 22 (11):1601-1606. doi:10.1002/mds.21577

35. Banaschewski T, Woerner W, Rothenberger A (2003) Premonitory sensory phenomena and suppressibility of tics in Tourette Syndrome - developmental aspects in children. Developmental Medicine and Child Neurology 45:700-703 
36. Heinrich H, Gevensleben H, Strehl U (2007) Annotation: neurofeedback - train your brain to train behaviour. J Child Psychol Psychiatry 48 (1):3-16. doi:JCPP1665 [pii]

10.1111/j.1469-7610.2006.01665.x

37. Tansey MA (1986) A simple and a complex tic (Gilles de la Tourette's syndrome): their response to EEG sensorimotor rhythm biofeedback training. Int J Psychophysiol 4 (2):91-97. doi:0167-8760(86)90002-4 [pii]

38. Breteler MHM, van Heeswijk L, Arns M, Verdellen C (2008) Psychologische interventies bij het syndroom van Gilles de la Tourette [Psychological interventions in Gilles de la Tourette syndrome]. Tijdschrift voor Neuropsychiatrie en Gedragsneurologie 7:158-164

39. Nagaia Y, Cavanna A, Critchley HD (2009) Influence of sympathetic autonomic arousal on tics: Implications for a therapeutic behavioral intervention for Tourette syndrome. Journal of Psychosomatic Research 67:599-605

40. Woods DW, Piacentini JC, Walkup JT (2007) Treating Tourette syndrome and tic disorders: A guide for practitioners. Guilford Press, New York

41. Conelea CA, Woods DW (2008) The influence of contextual factors on tic expression in Tourette's syndrome: a review. J Psychosom Res 65 (5):487-496. doi:S0022-3999(08)00216$\mathrm{X}$ [pii]

10.1016/j.jpsychores.2008.04.010

42. Packer LE (2005) Tic-related school problems: impact on functioning, accommodations, and interventions. Behav Modif 29 (6):876-899. doi:29/6/876 [pii]

$10.1177 / 0145445505279383$

43. Peterson BS, Cohen DJ (1998) The treatment of Tourette's syndrome: multimodal, developmental intervention. J Clin Psychiatry 59 Suppl 1:62-72; discussion 73-64

44. Dooley JM, Berna PM, Gordon KE (1999) Parent perception of symptom severity in Tourette's syndrome. Archives of Disease in Childhood 81:440-441 
45. Cutler D, Murphy T, Gilmour J, Heyman I (2009) The quality of life of young people with Tourette syndrome. Child Care Health Dev 35 (4):496-504. doi:CCH983 [pii]

10.1111/j.1365-2214.2009.00983.x

46. Kepley HO, Conners S (2007) Management of learning and school difficulties in children with Tourette syndrome. In: Woods DW, Piacentini JC, Walkup JT (eds) Treating Tourette syndrome and tic disorders: A guide for practitioners. Guilford Press, New York, pp 242-264 47. Wand RR, Matazow GS, Shady GA, Furer P, Staley D (1993) Tourette syndrome: associated symptoms and most disabling features. Neurosci Biobehav Rev 17 (3):271-275. doi:S0149-7634(05)80010-7 [pii]

48. Boudjouk PJ, Woods DW, Miltenberger RG, Long ES (2000) Negative peer evaluation in adolescents: Effects of tic disorders and trichotillomania. Child and Family Behavior Therapy $22: 17-28$

49. Friedrich S, Morgan SB, Devine C (1996) Children's attitudes and behavioral intentions toward a peer with Tourette syndrome. J Pediatr Psychol 21 (3):307-319

50. Woods DW, Fuqua RW, Outman RC (1999) Evaluating the social acceptability of persons with habit disorders: The effects of topography, frequency, and gender manipulation. Journal of Psychopathology and Behavioral Assessment 21:1-18

51. Woods DW, Marcks BA (2005) Controlled evaluation of an educational intervention used to modify peer attitudes and behavior toward persons with Tourette's Syndrome. Behav Modif 29 (6):900-912. doi:29/6/900 [pii]

$10.1177 / 0145445505279379$

52. Murphy T, Heyman I (2007) Group Work in Young People with Tourette Syndrome. Child and Adolescent Mental Health 12:46-48

53. Taubert KA (1999) Role of voluntary organizations in clinical care research and public policy. In: Leckman JF, Cohen DJ (eds) Tourette's syndrome-tics obsessions compulsions: 
Developmental psychopathology and clinical care. John Wiley \& Sons Inc, Hoboken, pp 399413

54. Griendt Jvd, Verdellen C, Verbraak M, Hoogduin C (Manuscript in preparation) The effect of exposure length on treatment outcome for tics in Tourette's syndrome: One hour sessions versus two hour sessions.
55. Gevensleben
$\mathrm{H}$, Holl
B, Albrecht
B, Vogel
C, Schlamp
D, Kratz O, Studer P,

Rothenberger A, Moll GH, Heinrich H (2009) Is neurofeedback an efficacious treatment for ADHD? A randomised controlled clinical trial. J Child Psychol Psychiatry 50 (7):780-789. doi:JCPP2033 [pii]

10.1111/j.1469-7610.2008.02033.x

56. Gevensleben H, Holl B, Albrecht B, Schlamp D, Kratz O, Studer P, Rothenberger A, Moll GH, Heinrich H (2010) Neurofeedback training in children with ADHD: 6-month follow-up of a randomised controlled trial. Eur Child Adolesc Psychiatry 19 (9):715-724. doi:10.1007/s00787-010-0109-5 